\title{
BIBLIOGRAPHY SECTION
}

WYSS, E., What is bibliometrics (in German), Nachrichten /Nouvelles/ Notizie, 57 (1) (1981), 4-7. (No address)

ZEIDNER, M, A., Who evaluates the evaluators? Journal of Technical Writing and Communication, 13 (3) (1983), 201-203. (327 Tacoma Street, New Orleans, LA 70124, USA)

ZIMAN, J., Citation heresy, New Scientist, 98 (1360) (1983), 649. (No address)

\section{Correction}

The correct data of an item erroneously and incompletely reported in the bibliography of volume $5(3)$, on page 133 :

WANG, J. K. C., Selection of periodicals: Cognitive statistical approach, Journal of Library and Information Science, 6 (1) (1980), 17-24. (Soochow University, Taipei, Taiwan) 